\title{
Increase in impact factor for the SMJ
}

Kian Keong Poh, FRCP, FACC

I June 2018, I was part of the faculty of an annual scientific meeting of a society in the United States and attended an editorial board meeting of the journal associated with the society. Its Editor-in-Chief (EIC) is a wise man who is completely dedicated to his job - it was obvious from the thorough reviewer and editorial comments for each submitted paper (whether the decision was to reject or revise) that a lot of effort was put into helping the authors. When I returned to Singapore, I found that the journal has maintained its high impact factor (IF) of about 7 in the 2017 Journal Citation Reports (JCR) published by Clarivate Analytics. ${ }^{(1)}$ At the same time, I was proud to learn that the Singapore Medical Journal (SMJ) has achieved an IF of 1.08 and ranks 100 out of 154 journals under the Medicine, General and Internal category of the JCR. This is an improvement from 2016 (Fig. 1) and is consistent with the aims that we set at the beginning of the year. ${ }^{(2)}$ With the global increase in the number of journals, some established journals reported falls in their IF this year. The SMJ is in the third quartile of its category, which includes top journals like the New England Journal of Medicine, the Lancet and the British Medical Journal. Their 2017 IF ratings are off the charts at 79, 53 and 23, respectively. The SMJ's improvement is a milestone, considering that its first IF rating was only received in recent years.

As most of our readers are aware, the IF is a journal-level performance metric that measures the frequency of a scholarly journal's contents being cited over a time period. Specifically, a journal's 2017 IF is calculated based on the number of citations in 2017 of articles published in 2015 and 2016. The IF has been a dominant performance measure for a long time, but many have also acknowledged that it is an imperfect tool. For one, the IF indicates the impact of a journal as a whole, and cannot be used as a proxy to measure the influence of an article or the calibre of a researcher. Some relatively newer metrics, such as Eigenfactor and SCImago Journal Rank, give higher weightage to citations from influential journals; CiteScore, a new metrics by Scopus, counts citations over three years of published documents; and Google Scholar h5-Index counts the number of articles, h, published in the past five years that have a minimum of $h$ citations. ${ }^{(3)}$ These new metrics provide alternative ways to evaluate scholarly impact, but how they will fare against the IF remains to be seen. In the words of Valentin Fuster, EIC of Journal of the American College of Cardiology - the IF is "here to stay, especially because many deans, government agencies, and employment panels use this as a performance measure". ${ }^{(4)}$

While it is important to maintain and even grow the IF, I strongly believe that the journal's primary purpose is to serve its readers and expand the body of scientific knowledge. The SMJ judges the merits of each and every submitted article based on not only its scientific rigour, but also its potential impact on

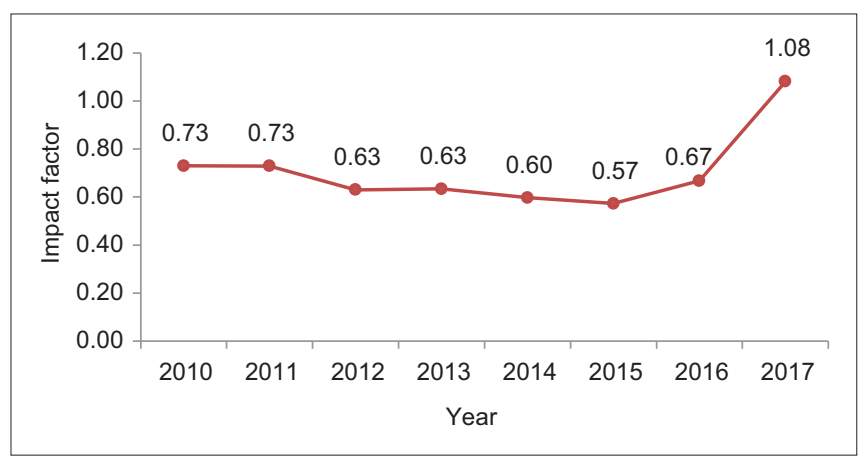

Fig. 1 The SMJ's impact factor from 2010 to 2017

clinical practice and relevance to all clinicians - from residents to experienced general practitioners and specialists. The proportion of original papers, reviews, continuous medical education articles and novel cases we publish monthly remains consistent, even though other article types could potentially attract more citations. For instance, international guidelines are more often cited than local guidelines, in part due to the smaller local author base. However, the latter are important to put medicine in a local perspective. ${ }^{(5)}$ Half of the SMJ's 260 articles published in 2015 and 2016 were cited at least once, with the most cited being original research papers. ${ }^{(1)}$ More will be cited in future, although they will not be included in the IF calculation. The SMJ will continue to publish high-quality local and regional papers, and echoing the sentiments of Elsevier's Sarah Huggett, I believe that "if we take care of the journal, the IF will take care of itself". ${ }^{(6)}$

Finally, I wish to thank my colleagues in the SMJ Editorial Board, and all the authors and reviewers who have helped to fill our journal with quality content. My deepest appreciation goes to the Singapore Medical Association Council for the support and editorial freedom it has given to me and my Board, as well as the editorial staff for their hard work in ensuring that the journal is edited and published in a timely manner every month. We will not rest on our laurels. It is my hope that the SMJ will not only continue to improve in its IF, but that our articles will help clinicians to better care for their patients and aid researchers in their scholarly pursuits.

\section{REFERENCES}

1. Clarivate Analytics. Web of Science. Available at: https://login.webofknowledge. com. Accessed July 7, 2018.

2. Poh KK. A time for reflection and thanks. Singapore Med J 2018; 59:1.

3. Measuring a journal's impact. Available at: https://www.elsevier.com/authors/ journal-authors/measuring-a-journals-impact. Accessed July 7, 2018.

4. Fuster V. Impact factor: a curious and capricious metric. J Am Coll Cardio 2017; 70:1530-1.

5. Tai ES, Chia BL, Bastian AC, et al. Ministry of Health Clinical Practice Guidelines: Lipids. Singapore Med J 2017; 58:155-66.

6. Huggett S. Impact factor ethics for editors: how impact factor engineering can damage a journal's reputation (June 4, 2012). Available at: https://www.elsevier. com/editors-update/story/journal-metrics/impact-factor-ethics-for-editors. Accessed July 7, 2018. 